\title{
Comparison of Chinese Tourists' Expectations and Perceptions on Seaside Resort Areas' Service Quality: A Case of Chinese Tourists in Southern Region of Thailand
}

\author{
Minyang Zhang ${ }^{1}$, \& Fuangfa Ampornstira ${ }^{1}$ \\ ${ }^{1}$ School of Management, Shinawatra University, Bangkok, Thailand \\ Correspondence: Minyang Zhang, School of Management, Shinawatra University, Bangkok, Thailand.
}

Received: April 13, 2020

Accepted: May 4, 2020

Online Published: May 8, 2020

doi:10.5539/ibr.v13n6p13

URL: https://doi.org/10.5539/ibr.v13n6p13

\begin{abstract}
The objectives of this study were to analyze the Chinese tourists' expectation and perception gaps of service quality in southern Thailand's seaside resorts, to study the items of service quality that are satisfied by Chinese tourists in southern Thailand's seaside resorts, to study the items of service quality that are dissatisfied by Chinese tourists in southern Thailand's seaside resorts. The researcher used the survey questionnaire to collect data from 400 Chinese tourists who visited seaside resort areas in the southern region of Thailand and used descriptive statistics.

The results found that Chinese tourists think some perceptions exceed their expectations, such as supporting online bookings in seaside areas, the staffs provide personalized service, the staffs are respectful, use polite language, smile service towards Chinese tourists, the seaside resorts have technical support. However, Chinese tourists think some perceptions can't reach their expectations, as for the price, it doesn't have a reasonable price for food items, accommodation, traffic, commodity, and entertainment. As for the staff, it doesn't have a first-class ability to handle emergencies, they can't provide fast services. As for the managers of resort areas, it doesn't have enough legal frameworks in protecting Chinese tourists.

The study recommends that the managers of seaside resort areas in southern Thailand need control of the cost of accommodation, food, transportation, commodities to be more rationalized. Additionally, managers should introduce laws and policies to protect the rights and interests of Chinese tourists, improve the ability of staff to handle emergencies and provide fast service for Chinese tourists.
\end{abstract}

Keywords: Chinese tourist, seaside resort area, service quality

\section{Introduction}

Tourism is one of the most important industries in Thailand. It promotes local economic development, increases local employment opportunities and increases people's income. Chinese tourists are a large population for Thailand tourism industries, the experience of Chinese tourists in the seaside resort areas has a strong research value for the tourism industry in Thailand, and Chinese tourists' expectations and perceptions play a key role in improving the service quality in southern seaside resort areas (Yang, 2014). The objectives of this study are to analyze the Chinese tourists' expectations and perception gaps in service quality in southern Thailand's seaside resorts. To study the items of service quality that are satisfied by Chinese tourists in southern Thailand's seaside resorts. To study the items of service quality that are dissatisfied by Chinese tourists in southern Thailand's seaside resorts. China is developing rapidly, people's living standards, cultural levels, purchasing power, etc. are constantly improving. Regularly updating the expectations and perceptions of Chinese tourists traveling in Thailand is particularly important for improving the quality of Thai tourism. There are many articles on studying tourism in Thailand as well as many articles on studying the seaside resort areas in Thailand. However, there are few published articles on the study of combining several seaside resort areas in Thailand, and few published articles on southern seaside resort areas. The theoretical implications of the study are combined three Thailand southern seaside resort areas to compare Chinese tourists' expectations and perceptions of service quality and have never been seen in previous research. The practical implications of the study are that help Thailand 's seaside resort areas to understand the latest information about Chinese tourists' expectations and actual evaluation of the destination's service quality, and contribute to managers to enhance the competitiveness of the 
southern Thailand seaside resort areas, to attract more Chinese tourists to Thailand. Improve the service quality of the southern Thai seaside resort, and promote the rapid and stable development of the Thailand tourism market.

\section{Literature Review}

Ren (2018) pointed out that the tourist expectation is to meet certain needs or aspirations, which are expected to be a short-lived belief that will determine the behavior. According to Li et al. (2011), tourists are expected toward travel due to six reasons, which consisted of the patience of the staff, privacy need services, clear marketing communications, reasonable price, word of mouth, and previous experience of the tourist. Expectations show the needs of people from the present to the future. In a service business, especially the tourism industry, it is important to study the expectations of tourists, as this will lead us to understand more of what travelers want to make use of their experience to meet their expectations and generate high satisfaction towards all products and services provided.

Bernstein et al. (2012) have described perception as the process that occurs after the stimulus has been interpreted as a feeling and what is meant by knowledge, experience, and understanding of a person. It is perceived as something that must be learned without learning or experience and will not cause recognition performance. Tourist perception is the psychological process by which tourists obtain information about tourist objects and tourist environmental conditions through their senses. Tourist perception constitutes the behavior environment of tourists. Tourist perception not only affects tourism decisions but also affects the evaluation of tourists (Chiu et al., 2016).

SERVQUAL is a multi-item scale with good reliability and validity, which helps companies better understand the assessment of service expectations and customer perceptions, and improve services. Parasuraman et al. (1994) state that SERVQUAL provides a basic framework through its expectation/perception format, which contains statements for five quality of service dimensions. The framework can be adjusted or supplemented as necessary to suit the characteristics of a particular organization or specific research needs. Five quality of service dimensions including tangibility, reliability, responsiveness, assurance (combining communication, credibility, security, competence, and courtesy) and empathy (combining understanding and understanding of customers with accessibility) (Saleh and Ryan, 2006).

Kotler (1999) mentioned that customer satisfaction as the customer's experience, comparing the customer's pre-purchase expectations with the post-purchase experience. Oliver (1981) stated that customer satisfaction is an assessment of a customer's specific transaction and reflects the relationship between the customer's expectations and their true experience with the products and services they receive. Expectations are short-term forecasts. Customer satisfaction is the embodiment of service quality. When the two are equal or the latter exceeds the former, customer satisfaction will appear. Customer satisfaction is influenced by the quality of products and services as well as customer sentiment. Customer satisfaction is the assessment of the customer's service after purchase, not their expectations (Zeithaml and Bitner, 1996). Pizam et al. (1978) define tourists' satisfaction as the result of a comparison between a tourist's experience and expectations. Swan and Combs (1976) stated that tourist satisfaction is a postconsumer attitude. Kolter (1999) considers tourist satisfaction as a comparison of the tourist's pre-tourism expectations with the post-tourism experience. Many scholars have mentioned that satisfaction was a comparison of customer expectations and perceptions.

\section{Method}

\subsection{Population and Sample}

The population for this research is Chinese tourists who are visiting seaside resort areas in southern region of Thailand. There are 3,660,106 Chinese tourists has been to Thailand southern seaside resort areas in 2017. Among them, the number of Chinese tourists to Phuket is 2,800,000, Koh Samui is 321,106 , Krabi is 539,000 (Jones and Salle, 2019).

Supposing to calculate a sample size of finite, when the original sample collected is more than 5 percent of the population size, the corrected sample size is determined by using the Yamane's formula. Based on this study, the population is $3,660,106$, the error level is 0.05 , the calculation for the required sample size will be as follows:

$$
\mathrm{n}=\frac{3660106}{\left(1+3660106^{*} 0.05^{2}\right)}=399.956 \approx 400
$$

By applying Taro Yamane formula to derive the sample size for the survey on the population is finite, the sample size from the computation was 400 samples. 


\subsection{Reliability and Validity}

The questionnaire was tested with 30 Chinese tourists who visited Thailand southern seaside resort areas. The reliability value was calculated by using Cronbach's alpha to ensure whether there was internal consistency within the items. The Alpha value of the pilot test test was 0.877 , it indicated that the questionnaire of this research was highly reliable.

The index of item-objective congruence (IOC) is adopted in this study to test development for evaluating content validity at the item development stage (Rovinelli, \& Hambleton, 1976). The result of the IOC test was 0.7 , the designed questions of this research are acceptable.

\subsection{Questionnaire Design}

The questionnaire consists of two parts. The first part is to survey the basic information of tourists. The second part is to survey the tourists' expectations and perceptions for the service quality of the seaside resort in southern Thailand and using a five-point Likert's scale as the response format. According to the dimension of SERVQUAL, marketing mix and external business. The researcher based on these dimensions, including tangibility, reliability, responsiveness, assurance, empathy, 7Ps (product, promotion, people, place, process, price, physical evidence), landscape, traffic, shopping, entertainment, the related questions were designed.

\subsection{Data Collection}

According to the number of Chinese tourists to Phuket was 2,800,000, Koh Samui was 321,106, Krabi was 539,000 in 2017 (Jones and Salle, 2019). Researcher issued questionnaire followed the above proportion that Phuket was $76.5 \%$, Koh Samui was $8.8 \%$, Krabi was $14.7 \%$. A total number of 428 questionnaires were distributed and 400 were completed. Thus, the response rate was 93.5 percent, the number of Chinese tourists in Phuket was 306, the number of Chinese tourists in Koh Samui was 36, and the number of Chinese tourists in Krabi was 58.

\section{Results}

\subsection{Demographic Analysis of the Respondents}

The majority of the Chinese tourists coming to Thailand southern seaside resort areas are female, ages are between 18-24 years old, unmarried, hold bachelor degrees, students, monthly salary between 3,000-5,999 Yuan. The majority of the Chinese tourists come from east China and north China, they choose to stay in Thailand southern seaside resort areas for 2 - 4 days. Before coming to Thailand southern seaside resort areas, the majority of the Chinese tourists got travel information from the websites and other social media. The majority of the Chinese tourist choose to come to Thailand southern seaside resort areas with friends, and never been to Thailand southern seaside resort areas before.

\subsection{Comparison of Chinese Tourists' Expectations and Perceptions}

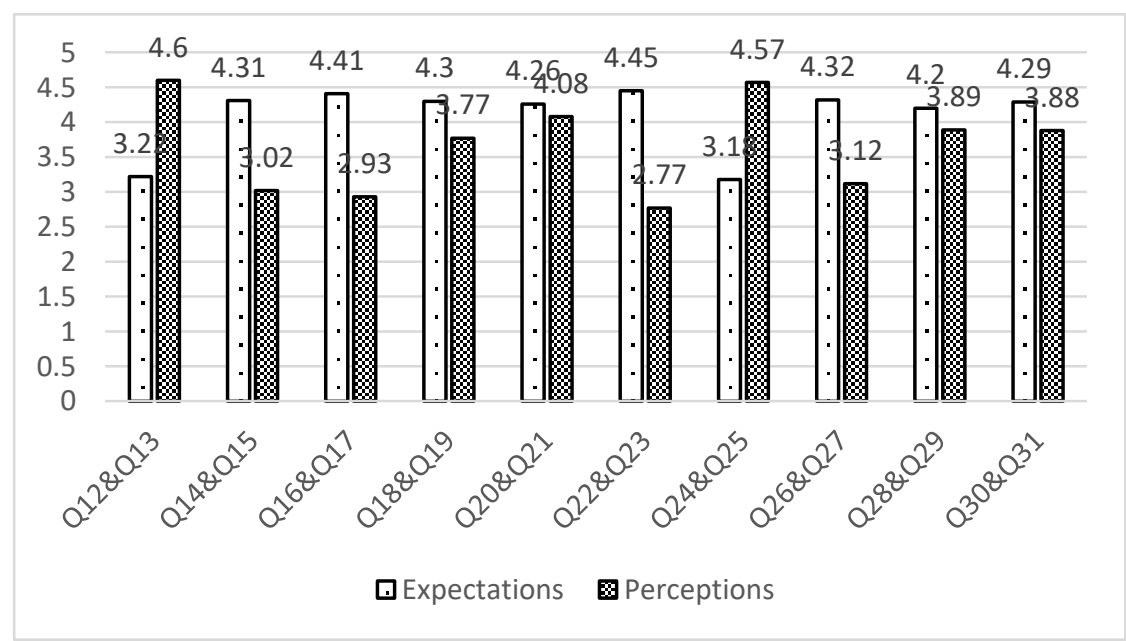

Figure 1. Comparison of Chinese Tourists' Expectations and Perceptions of SERVQUAL

The result from Figure 1 illustrated that from the SERVQUAL, having first-class ability to handle emergencies is the biggest gap between expectations and perceptions (gap=1.68, rank 1), followed by having a legal framework 
in protecting Chinese tourists (gap=1.48, rank 2), followed by being respectful, use polite language, smile service towards Chinese tourists (gap=-1.39, rank 3), followed by having technical support, such as getting information on travel Apps, using online payment, etc. (gap=-1.38, rank 4), followed by having a well-developed infrastructure (gap=1.29, rank 5), followed by having sufficient funds to support the development of local tourism ( $\mathrm{gap}=1.20$, rank 6 ), followed by having excellent public security situation (gap=0.53, rank 7 ), followed by having friendly staffs (gap $=0.41$, rank 8 ), followed by paying attention to the expectations of Chinese tourists. Such as actively developing tourism projects suitable for Chinese tourists (gap=0.31, rank 9), followed by being friendly towards Chinese tourists and welcome Chinese tourists to travel (gap=0.18, rank 10).

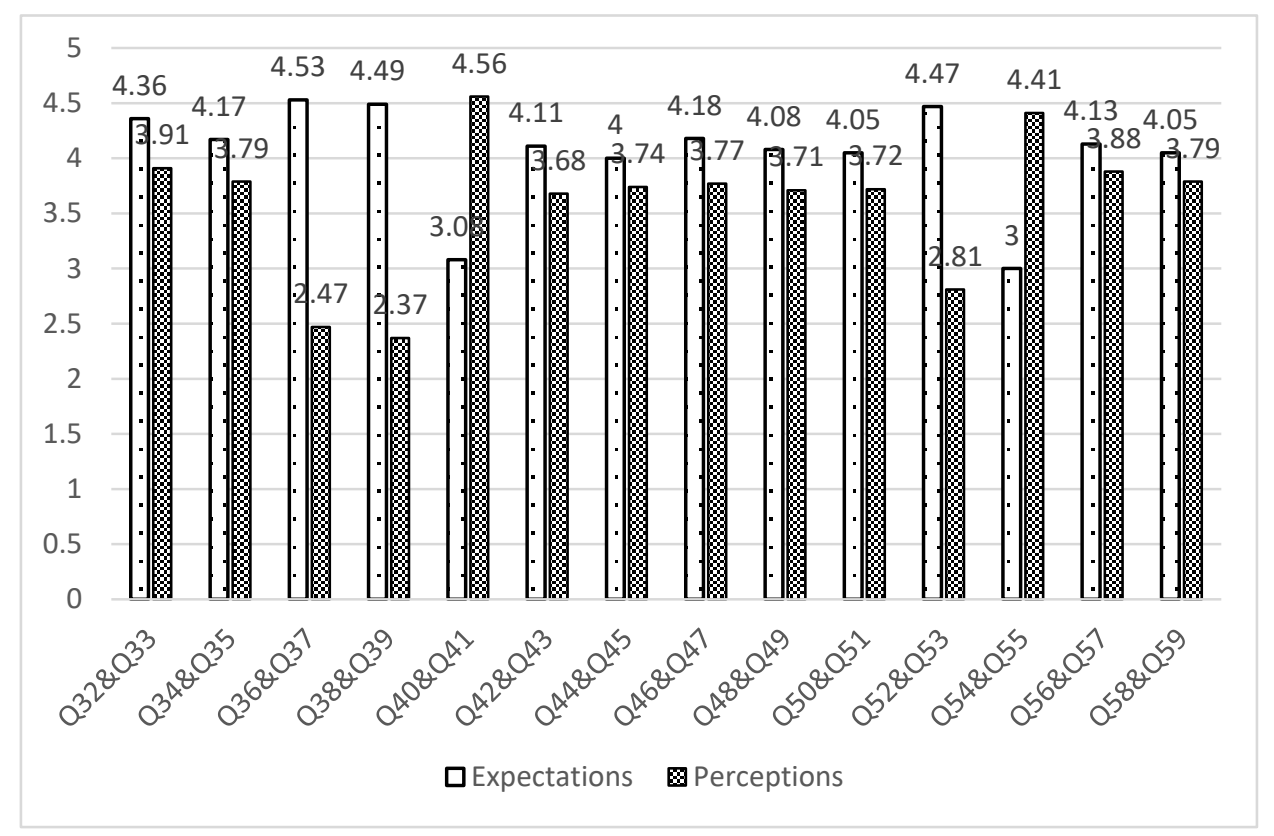

Figure 2. Comparison of Chinese Tourists' Expectations and Perceptions of Marketing Mix Factors

The result from Figure 2 illustrated that from the marketing mix factors, having a reasonable price for food items is the biggest gap between expectations and perceptions ( $\mathrm{gap}=2.12$, rank 1), followed by having a reasonable accommodation price (gap=2.02, rank 2), followed by being staffs who provide fast services ( $g a p=1.66$, rank 3 ), followed by supporting online bookings (gap=-1.48, rank 4), followed by being able to provide personalized service to Chinese tourists (gap=-1.41, rank 5), followed by being clean and sanitary in the hotel (gap $=0.45$, rank 6), followed by setting up pre-sale tickets point (gap=0.43, rank 7), followed by providing services as advertised to Chinese (gap $=0.41$, rank 8 ), followed by having a first-class tour guide service team ( $g a p=0.38$, rank 9 ), followed by having trustworthy staffs (gap=0.37, rank 10), followed by providing professional service towards Chinese tourists (gap $=0.37$, rank 11), followed by having special promotions for Chinese tourists and having a brochure for major tourist attractions and around the district (gap=0.26, rank 12), followed by having staffs with healthy image, be well-dressed, and have excellent service skills (gap=0.25, rank 14). 


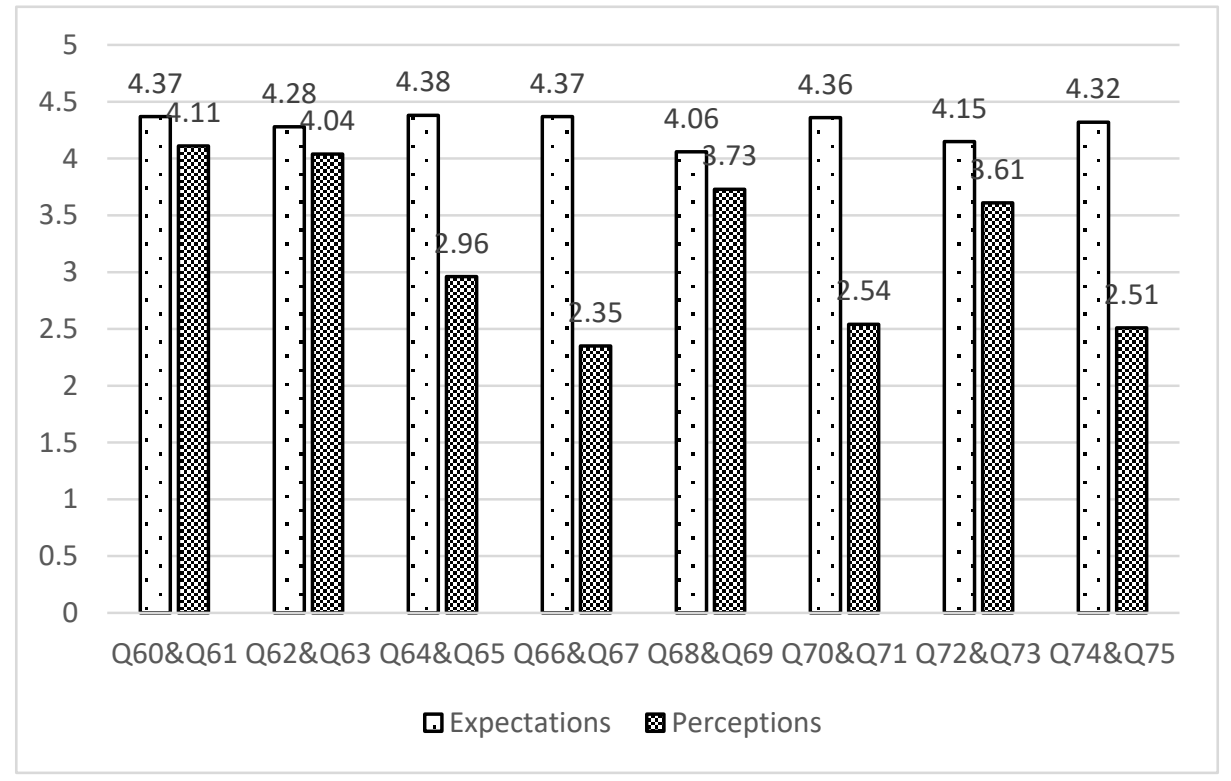

Figure 1. Comparison of Chinese Tourists' Expectations and Perceptions of External Business Factor

The result from Figure 3 illustrated that from the External Business Factor, having reasonable traffic cost is the biggest gap between expectations and perceptions ( $g a p=2.02$, rank 1 ), followed by having reasonable commodity prices (gap $=1.82$, rank 2), followed by having reasonable price at entertainment (gap=1.81, rank 3 ), followed by having convenient and easy access to transportation in the area (gap=1.42, rank 4), followed by having facilities for Chinese tourists recreational (gap $=0.54$, rank 5), followed by having stores that sell souvenirs and special local products (gap $=0.33$, rank 6 ), followed by having unique natural tourism landscape (gap=0.26, rank 7), followed by keeping a good memory for tourists (gap=0.24, rank 8).

\section{Discussion}

From the results, the biggest gap of dissatisfaction of Chinese tourists in the marketing mix factor is that Chinese tourists think that the food price has not met their expectations, and the gap has reached 2.12. The price of accommodation ranked second, and gap $=2.08$, which did not meet their expectations. The external business factor involved traffic prices, commodity prices, and entertainment prices did not meet the expectations of Chinese tourists, the gap has reached 2.02, 1.82, and 1.42 respectively. It can be seen that the price item of Chinese tourists for the seaside resort areas in southern Thailand as a whole are lower than expected. From the demographic results, we can see that, first, most tourists who came to the southern seaside resort areas of Thailand had a monthly salary of 3,000-5,999 Yuan, few high-income earners, and second, the majority of occupations were students, because students had little income. So the prices item were lower than Chinese tourists' expectations.

It can also be seen from the results that the biggest gap of satisfaction of Chinese tourists in the marketing mix factor was supporting online bookings, the gap reached 1.48. And in the SERVQUAL factor, there was technical support, such as getting information on travel Apps, using online payment, etc., the gap was 1.38. Because Thailand is widely used in Alipay, WeChat Pay, UnionPay, Chinese app booking, etc., which is convenient for Chinese tourists. In terms of services, providing personalized service to Chinese tourists and being respectful, use polite language, smile service towards Chinese tourists also exceeded the expectations of Chinese tourists, which were gap=1.41 and gap=1.39 respectively. This was consistent with Vatcharamon (2016) mentioned that the tourism industry in Thailand was mainly a service of smiles and Chinese tourists were highly satisfied with the smile services of Thailand. However, in terms of handling emergencies and fast services, the perception of Chinese tourists was lower than expected, which was related to the different ways of doing things in the two countries. The Chinese were used to doing things quickly and efficiently, while the efficiency of the Thai people may be accustomed to regular services. The Chinese were not used to it, causing Chinese tourists to be dissatisfied with the Thais' handling of emergency affairs and fast service.

Chinese tourists were also below perceptions for an item of having a legal framework in protecting Chinese tourists, with a gap of 1.48. Wang (2012) mentioned that the tourism authority of Thailand has a strict 
management system. When traveling on Phuket, you can often see a tourist policeman in uniform, which is one of the characteristics of Thailand. If the rights are violated, tourists can complain directly to them and they will get justice for you. The Phuket government has taken many other steps to protect the interests of tourists. So it is contradicted Wang who stated.

\section{Conclusion}

Chinese tourists think some perceptions in Thailand southern seaside resort areas can't reach their expectations. As for the price, it doesn't have a reasonable price for food items, accommodation, traffic, commodity, and entertainment. As for the staff, they don't have first-class ability to handle the emergency, can't provide fast services. As for the managers of seaside resort areas, it doesn't have enough legal frameworks in protecting Chinese tourists, doesn't have convenient and easy access to transportation in the seaside resort area, etc.

However, Chinese tourists think some perceptions in Thailand southern seaside resort areas exceed their expectations. First, the seaside resort areas are supporting online bookings, followed by the staffs provide personalized service to Chinese tourists, followed by the staffs are respectful, use polite language, smile service towards Chinese tourists, last, the seaside resort areas have technical support, such as getting information on travel Apps, using online payment, etc.

The theoretical implications of the study are combined three Thailand southern seaside resort areas to compare Chinese tourists' expectations and perceptions of service quality and have never been seen in previous research. The three seaside resort areas are combined for analysis, compared with previous articles that only studied one seaside resort area, this study is more representative. So this study adds theoretical contributions to the study of the seaside resort area in southern Thailand.

The practical implications of the study are that help Thailand 's seaside resort areas to understand the latest information about Chinese tourists' expectations and actual evaluation of the destination's service quality, and contribute to managers to enhance the competitiveness of the southern Thailand seaside resort areas, to attract more Chinese tourists to Thailand. Improve the service quality of the southern Thai seaside resort, and promote the rapid and stable development of the Thailand tourism market.

Some limitations can be identified, First, the findings from this study apply to Chinese tourists and are not applied to tourists from other countries because they have different expectations and perceptions. Second, this study only uses quantitative methods and lacks qualitative data, which may cause data limitations, using only a single method, only part of the information can be obtained, and much other useful information is ignored and omitted, which makes it difficult to make a comprehensive and accurate conclusion.

The study recommends that the managers of seaside resort areas in southern Thailand need control of the cost of accommodation, food items, transportation, commodities to be more rationalized. To set up reasonable prices, they need to control individual or collective price hike, rectifying the phenomenon of disrupting market prices and stabilizing market prices. With better price management, thereby attracting more Chinese tourists to visit seaside resort areas in southern Thailand. Additionally, managers should Introduce laws and policies to protect the rights and interests of Chinese tourists in Thailand, improve the ability of staff to handle emergencies and provide fast service for Chinese tourists. Self-adjustment to reach the most anticipated aspects of Chinese tourists to create seaside resort areas visiting to reach the Chinese tourists' most satisfaction.

\section{References}

Bernstein, D. A., Penner, L. A., Clarke-Stewart, A., \& Roy, E. J. (2012). Phychology (9th ed.). Belmont, America: Wadsworth Cengage Learning.

Chiu, W. S., Zeng, S. H., \& Cheng, P. S. T. (2016). The influence of destination image and tourist satisfaction on tourist loyalty: a case study of Chinese tourists in Korea. International Journal of Culture, Tourism and Hospitality Research, 10(2), 223-234. https://doi.org/10.1108/IJCTHR-07-2015-0080

Jones, L. L., \& Salle, I. (2019). Thailand hotel market research prepared for S hotels and resorts company limited. FINAL-Thailand Hotel Market Research, 1(1), 1-174. Retrieved from http://webcache.googleusercontent.com/search?q=cache:_mpFyad0mNEJ:market.sec.or.th/public/ipos/IPO SGetFile.aspx\%3FTransID\%3D250826\%26TransFileSeq\%3D58+\&cd=1\&hl=zh-CN\&ct=clnk\&gl=th

Kotler, P. (1999). Marketing management (10th ed.). New Jersey, NJ:Prentice-Hall.

Li, X., Lai, C., Harrill, R., Kline, R., \& Wang, L. (2011). When east meets west: An exploratory on study on Chinese outbound tourists' travel expectations. Tourism Management, 32(4), 741-749. https://doi.org/10.1016/j.tourman.2010.06.009 
Oliver, R. L. (1981). Measurement and evaluation of satisfaction processes in retailing setting. Journal of Retailing, 57, 25-48. Retrieved from https://psycnet.apa.org/record/1984-10995-001

Parasuraman, A., Zeithaml, V. A., \& Berry, L. L. (1994). Reassessment of expectations as a comparison standard in measuring service quality: implications for future research. Journal of Marketing, 58(1), 111-124. https://doi.org/10.1177/002224299405800109

Pizam, A., Neumann, Y., \& Reichel, A. (1978). Dimensions of tourism satisfaction with a destination area. Annals of Tourism Research, 5, 314-322. https://doi.org/10.1016/0160-7383(78)90115-9

Ren, H. K. (2018). A study of the tourists expectation, satisfaction and revisiting intention in the Neiwan, Hsinchu. International Journal of New Development in Engineering and Society, 2(1), 43-49. https://francis-press.com/uploads/papers/0FtiAYCPK6kruDGI4n5zJ5vCbSijsAHDRox14hQQ.pdf

Rovinelli, R. J., \& Hambleton, R. K. (1976). On the use of content specialists in the assessment of criterion-referenced test item validity. Dutch Journal for Educational Research, 2, 49-60. Retrieved from https://www.semanticscholar.org/paper/On-the-Use-of-Content-Specialists-in-the-Assessment-Rovinelli-Ha mbleton/14a18d4b0d4694911ff32b20de7f1f090088012e

Saleh, F., \& Ryan, C. (2006). Analyzing Service Quality in the Hospitality Industry using the SERVQUAL model. Services Industries Journal, 11(3), 324-345. https://doi.org/10.1080/02642069100000049

Vatcharamon, Y. (2016). A study on the consumption behavior of inbound tourists in Thailand--A case study of Chinese tourists (Master's thesis). Heilongjiang University, Heilongjiang, Harbin.

Wang, L. L. (2012). Phuket- A Free Tropical Paradise. Foreign Investment in China, 3(23), 192-194. Retrieved from https://kns.cnki.net/KCMS/detail/detail.aspx?dbcode=CJFQ\&dbname=CJFD2012\&filename=WQZG01223 140\&v=MjU0MzZWNy9CTWp6UmFiRzRIOVBPckk1QlpJUjhlWDFMdXhZUzdEaDFUM3UcldNMUZy Q1VSN3FmWStacEZpbm4=

Yang, Y. N. (2014). A brief discussion on the sustainable development of tourism in Krabi. Journal of Educational Institute of Jilin Province, 30(4), 113-114. Retrieved from https://kns.cnki.net/KCMS/detail/detail.aspx?dbcode=CJFQ\&dbname=CJFD2014\&filename=JLJB2014040 50\&v=MzEzMzQ5QVpJUjhlWDFMdXhZUzdEaDFUM3FUcldNMUZyQ1VSN3FmWStacUZDcmhVYi9 NTHIIQmJMRzRIOVhNcTQ=

Zeithaml, V. A., \& Bitner, M. J. (1996). Service marketing. New York, NY: McGraw-Hill.

\section{Copyrights}

Copyright for this article is retained by the author(s), with first publication rights granted to the journal.

This is an open-access article distributed under the terms and conditions of the Creative Commons Attribution license (http://creativecommons.org/licenses/by/4.0/). 